\title{
RET Proto Oncogene Mutation Detection and Medullary Thyroid Carcinoma Prevention
}

\author{
Marjan Zarif Yeganeh, Sara Sheikholeslami, Mehdi Hedayati*
}

\begin{abstract}
Thyroid cancer is the most common endocrine neoplasia. The medullary thyroid carcinoma (MTC) is one of the most aggressive forms of thyroid malignancy,accounting for up to $10 \%$ of all types of this disease. The mode of inheritance of MTC is autosomal dominantly and gain of function mutations in the RET proto-oncogene are well known to contribute to its development. MTC occurs as hereditary (25\%) and sporadic $(\mathbf{7 5 \%})$ forms. Hereditary MTC has syndromic (multiple endocrine neoplasia type 2A, B; MEN2A, MEN2B) and non-syndromic (Familial MTC, FMTC) types. Over the last two decades, elucidation of the genetic basis of tumorigenesis has provided useful screening tools for affected families. Advances in genetic screening of the RET have enabled early detection of hereditary MTCs and prophylactic thyroidectomy for relatives who may not show any symptom sof the disease. In this review we emphasize the main RET mutations in syndromic and non syndromic forms of MTC, and focus on the importance of RET genetic screening for early diagnosis and management of MTC patients, based on American Thyroid Association guidelines and genotype-phenotype correlation.
\end{abstract}

Keywords: Genetic screening - MEN2A - MEN2B - RET proto-oncogene - medullary thyroid cancer

Asian Pac J Cancer Prev, 16 (6), 2107-2117

\section{Introduction}

Neuroendocrine tumors (NETs) include a group of neoplasms of the neuroendocrine cells. The majority of NETs are sporadic. However, some of them may occur as familial inherited syndromes, such as multiple endocrine neoplasia type 1 (MEN1) and multiple endocrine neoplasia type 2 syndrome (MEN2), von Hippel Lindau (VHL) syndrome, neurofibromatosis, and tuberosclerosis (Oberg, 2013). The term MEN was introduced by Steiner et al in 1968 to describe disorders that include a combination of endocrine tumors (Steiner et al., 1968). Over the last two decades, the genetic basis of tumorgenesis in these familial syndromes has been explained, which providing clinicians with useful screening tools for early diagnosis of affected families and even prevention of the disease in unaffected members (Öberg, 2013). This review explains briefly the medullary thyroid carcinoma, MEN2 syndromes, and mutations found in the main exons of RET proto oncogene and the usefulness of RET genetic screening in MTC management.

\section{Medullary Thyroid Carcinoma}

Thyroid cancer is the most common endocrine neoplasia and accounts for $1 \%$ of all human cancers. Medullary thyroid carcinoma (MTC) is a rare malignant tumor which was first described by Jaquet in the German literature as "malignant goiter with amyloid" (AJ, 1906). In 1959, Hazard et al. (1959) provided a definitive histological description, while Williams suggested that MTC originated from the calcitonin $(\mathrm{Ct})$ secreting parafollicular $\mathrm{C}$ cells of the thyroid. Parafollicular $\mathrm{C}$ cells derive from the neural crest (Williams, 1966) and share a common neuroectodermal origin with the adrenal medulla. These cells secrete calcitonin, a hormone that plays an important role in the calcium regulation of certain animals but not in humans (Randolph and Maniar, 2000; Strosberg, 2013).

MTC accounts for $5-10 \%$ of all thyroid cancers (Leboulleux et al., 2004) and for $13.4 \%$ of all thyroid cancer-related deaths (Kebebew et al., 2000; Xu et al., 2012). The reported 10 -year mortality rate for patients with MTC varies from $13.5 \%$ to $38 \%$ (Girelli et al., 1998; Modigliani et al., 1998). The Surveillance, Epidemiology, and End Results (SEER) program of the National Cancer Institute showed that MTC patients had a median age of 50 years at diagnosis and were white in many cases (Mulligan et al., 1993; Roman et al., 2006).

The mentioned tumors account for about 1200 new cancer diagnoses each year in the United States (2\% of the 56500 new thyroid cancer cases in 2012) (Siegel et al., 2012). Prognosis can be affected by several factors, such as age, sex, tumor stage, and grading. In general, 
patients with tumors confined to the thyroid gland have a 10 -year survival rate greater than $95 \%$, whereas patients with regional stage disease had an overall survival rate of $75 \%$. Patients with distant metastases at diagnosis have a poor prognosis, with only $40 \%$ surviving 10 year (Roman et al., 2006; Agrawal et al., 2013). If MTC is diagnosed and treated at an early stage, the prognosis of disease will generally favorable, with 10 -year survival rates of 70-80\% (Roman et al., 2006). Unfortunately, at the time of diagnosis, up to $70 \%$ of patients with MTC have cervical lymph node metastasis, $15 \%$ have symptoms of local invasion such as hoarseness or dysphagia, and $10 \%$ have distant metastasis (Scollo et al., 2003; Quayle and Moley, 2005).

Surgery is the basis of therapy, total thyroidectomy with bilateral central lymph node dissection is recommended for almost all patients (Kloos et al., 2009). Patients typically die of widespread metastasis affecting liver, lung, and bone or locally aggressive disease with tracheal or esophageal invasion (Agrawal et al., 2013).

MTC can occur as either a sporadic (non-familial) or hereditary disease (Campbell et al., 2013). About 70-80\% of MTC cases occur as a sporadic form. Sporadic MTC (sMTC) can arise clinically at any age but its incidence peaks among the fourth and sixth decade of life, with a female dominance of $60 \%$ to $40 \%$ (Roman et al., 2006). The peak incidence of hereditary MTC (hMTC) can be diagnosed earlier, depending on the availability of genetic and biochemical screenings (LiVolsi, 1997).

Patients with sMTC usually present a solitary and palpable thyroid nodule or cervical lymph node. Most tumors occur in the upper and central areas of the thyroid where $\mathrm{C}$ cells are present at higher concentrations. The diagnosis is usually made on fine-needle aspiration (FNA). On average, more than $50 \%$ of patients have locoregional lymph node involvement at diagnosis and many present with palpable cervical adenopathy (Moley and DeBenedetti, 1999). Large primary tumor size and multifocality of tumors increases the risk of lymph node involvement (Machens et al., 2007). Distant metastases outside the neck, in the liver, lungs or bones are observed in about $10 \%-20 \%$ of patients at diagnosis (Saad et al., 1984). These patients may present with hormonal symptoms such as flushing and diarrhea, caused by excess secretion of calcitonin (Strosberg, 2013).

The hMTC form accounts for $25 \%$ of all MTC cases and it has autosomal dominant inheritance (Figlioli et al., 2013). The estimated prevalence is 2.5 per 100,000 (one in 30000 ) in the general population (Brauckhoff et al., 2008). hMTC characteristically presents as a multifocal process with $\mathrm{C}$-cell hyperplasia $(\mathrm{CCH})$ as the precursor lesion to MTC. Only familial primary $\mathrm{CCH}$ is a preneoplastic lesion (LiVolsi, 1997).

hMTC can be divided into three types: multiple endocrine neoplasia type 2A (MEN2A, 55-60\% of all cases), multiple endocrine neoplasia type 2B (MEN2B, $5 \%-10 \%$ ), and familial MTC alone (FMTC, 35\%-40\%) (Öberg, 2013), however more recent reports showed that FMTC as the most prevalent type of hMTC (up to 58\%) (Romei et al., 2011). These three types differ with respect to incidence, genetics, age-related penetrance, association with other diseases, aggressiveness of MTC, and prognosis (Brandi et al., 2001; Kloos et al., 2009).

MEN2 occurs in 1:200,000 live births (Moline and Eng, 2011) and is an autosomal-dominant inherited tumor syndrome with a prevalence of $1 / 30,000-1 / 40,000$ individuals (Campbell et al., 2013; Figlioli et al., 2013),

In the germline DNA of patients with MEN2, activating mutations in the RET (REarranged during Transfection) proto oncogene are found in virtually all cases (Agrawal et al., 2013). The duration for the progression from $\mathrm{CCH}$ to microscopic carcinoma in MEN2 remains unclear and it may take years; also the age of transformation from $\mathrm{CCH}$ to MTC varies with different germline RET mutations. MTC in MEN2 patients is multicentric and concentrated in the upper third of the thyroid gland (Costante et al., 2007).

An early manifestation of all MEN2 syndromes is parafollicular C-cell hyperplasia, which eventually progresses to multicentric neoplasia (Strosberg, 2013). Parafollicular C cells associated with both germline and somatic RET mutations and secrete both calcitonin and carcinoembryonic antigen (CEA), which can be used as tumor markers to screen for tumor recurrence (Campbell et al., 2013).

Advances in genetic screening have enabled early detection of hMTCs and prophylactic thyroidectomy for affected kindreds (Strosberg, 2013). Each variant of MEN2 results from a different mutation of the RET gene with good genotype-phenotype correlations (Raue and Frank-Raue, 2012).

\section{Multiple Endocrine Neoplasia Type 2A}

According to the literatures, MEN2A is the most common form of MEN2 syndrome (Frank-Raue et al., 2007; Raue and Frank-Raue, 2012). It makes up about $55 \%-80 \%$ or even $90 \%$ of cases of MEN2 and hMTC (Eng et al., 1996; Zbuk and Eng, 2007; Moline and Eng, 2011).

MEN2A, also known as "Sipple syndrome" was originally described by Sipple (Sipple, 1961). In 1961, he introduced a man who died of intracranial hemorrhage and autopsy findings were consistent with pheochromocytoma (PHEO), MTC, and parathyroid hyperplasia. The following year, Cushman (Cushma Jr, 1962) put a link between these endocrine tumors, which led to the classification of MEN2 as a unique entity.

Today, MEN2A is defined by MTC, bilateral PHEO, and multiple tumors of the parathyroid glands (parathyroid adenomas, primary hyperparathyroidism or HPT), within a single patient or family (Raue and Frank-Raue, 2012). The respective frequency of these tumors are $90 \%-100 \%$ for MTC (the penetrance of MTC in families with MEN2A is 100\%) (Campbell et al., 2013), 40\%-50\% for PHEO, and $10 \%-25 \%$ for parathyroid hyperplasia (Raue and FrankRaue, 2012). MTC is generally the first manifestation of MEN2A and presents when patients are between 5 and 25 years of age. Diarrhea, the most frequent systemic manifestation, occurs in affected individuals with a plasma calcitonin concentration of more than $10 \mathrm{ng} / \mathrm{mL}$ and infers a poor prognosis. Patients with MTC typically present with a neck mass or neck pain, usually before age 35 years. Up to $70 \%$ of such individuals already have cervical lymph 
node metastases (Cohen and Moley, 2003).

PHEO usually presents after MTC or concomitantly; however, it is the first symptom in $13-27 \%$ of individuals with MEN2A. PHEO in persons with MEN2A and
MEN2B are diagnosed at an earlier age, have subtler symptoms, and are more likely to be bilateral than sporadic tumors (Pacak et al., 2005).

HPT in MEN2A is typically mild and may range from

Table 1. Genotype-Phenotype Correlations and Risk Levels for Aggressive Medullary Thyroid Cancer (Kloos et al., 2009)

\begin{tabular}{|c|c|c|c|c|}
\hline Mutation Location & Exon & Mutation & Phenotype & ATA Risk Level \\
\hline Extra cellular cadrerine like domain & 5 & G321R & FMTC/MEN2A & A \\
\hline \multirow[t]{25}{*}{ Extra cellular cysteine rich domain } & \multirow[t]{10}{*}{8} & C515S & FMTC/MEN2A & A \\
\hline & & 532duplication & FMTC & A \\
\hline & & $529 / 531$ & FMTC & $?$ \\
\hline & & G533C & FMTC/MEN2A & A \\
\hline & & 532duplication & FMTC & A \\
\hline & & 531/9bp duplication & FMTC/MEN2A & A \\
\hline & & R600Q & FMTC/MEN2A & A \\
\hline & & K603E & FMTC/MEN2A & A \\
\hline & & K603Q & FMTC & A \\
\hline & & Y606C & FMTC & A \\
\hline & \multirow[t]{10}{*}{10} & $\mathrm{C} 609 \mathrm{~F} / \mathrm{R} / \mathrm{G} / \mathrm{S} / \mathrm{Y}$ & FMTC/MEN2A/HSCR & B \\
\hline & & C611R/G/F/S/W/Y & FMTC/MEN2A/ HSCR & $\mathrm{B}$ \\
\hline & & C618R/G/F/S/Y & FMTC/MEN2A/ HSCR & $\mathrm{B}$ \\
\hline & & $\mathrm{C} 620 \mathrm{R} / \mathrm{G} / \mathrm{F} / \mathrm{S} / \mathrm{W} / \mathrm{Y}$ & FMTC/MEN2A/ HSCR & B \\
\hline & & $\mathrm{C} 630 \mathrm{R} / \mathrm{F} / \mathrm{S} / \mathrm{Y}$ & FMTC/MEN2A & B \\
\hline & & D631Y & FMTC & $\mathrm{B}$ \\
\hline & & 633 & MEN2A & '?' \\
\hline & & 633/9bpduplication & FMTC/MEN2A & B \\
\hline & & $634 / 12 b p$ duplication & FMTC/MEN2A & $\mathrm{B}$ \\
\hline & & C634R & MEN2A/CLA & $\mathrm{C}$ \\
\hline & \multirow[t]{5}{*}{11} & C634G/F/S/W/Y & FMTC/MEN2A/CLA & $\mathrm{C}$ \\
\hline & & 634/12bp duplication & MEN2A & B \\
\hline & & 635/insertion ELCR/T636P & FMTC/MEN2A & A \\
\hline & & 637 & MEN2A & $?$ \\
\hline & & S649L & FMTC/MEN2A & A \\
\hline \multirow{30}{*}{ Intra cellular tyrosine kinase domain } & \multirow[t]{8}{*}{13} & K666E & FMTC/MEN2A & A \\
\hline & & E768D & FMTC/MEN2A/ sMTC & A \\
\hline & & N777S & FMTC & A \\
\hline & & 778 & FMTC & $?$ \\
\hline & & N776S & FMTC/MEN2A & A \\
\hline & & 781 & FMTC & $?$ \\
\hline & & L790F & FMTC/MEN2A & A \\
\hline & & Y791F & FMTC/MEN2A & A \\
\hline & \multirow[t]{11}{*}{14} & V804L & FMTC/MEN2A & A \\
\hline & & V804M & FMTC/MEN2A/sMTC & A \\
\hline & & V804M+E805K & MEN2B & $\mathrm{D}$ \\
\hline & & $\mathrm{V} 804 \mathrm{M}+\mathrm{Y} 806 \mathrm{C}$ & MEN2B & $\mathrm{D}$ \\
\hline & & G819K & FMTC & A \\
\hline & & $\mathrm{R} 833 \mathrm{C}$ & FMTC/ MEN2B & A \\
\hline & & R844Q & FMTC/ MEN2B & $\mathrm{A}$ \\
\hline & & V804M/E805K & MEN 2B & $\mathrm{D}$ \\
\hline & & V804M/Y806C & MEN 2B & $\mathrm{D}$ \\
\hline & & $804 / 844$ & FMTC & '?' \\
\hline & & 852 & FMTC & ‘?’ \\
\hline & \multirow[t]{4}{*}{15} & R866W & FMTC/MEN2A & A \\
\hline & & 876 & FMTC & ‘?’ \\
\hline & & $\mathrm{A} 883 \mathrm{~F}$ & MEN2B/sMTC & $\mathrm{D}$ \\
\hline & & S891A & FMTC/MEN2A/ & A \\
\hline & \multirow[t]{4}{*}{16} & R912P & FMTC/MEN2A/ MEN2B & A \\
\hline & & M918T & sMTC/MEN2B & $\mathrm{D}$ \\
\hline & & 920 & sMTC/MEN2B & $\mathrm{D}$ \\
\hline & & 922 & sMTC/MEN2B & $\mathrm{D}$ \\
\hline & $13 / 14$ & V804M+V778I & FMTC/MEN2A & $\mathrm{B}$ \\
\hline & $14 / 15$ & $\mathrm{~V} 804 \mathrm{M}+\mathrm{S} 904 \mathrm{C}$ & MEN2B/MEN2A & $\mathrm{D}$ \\
\hline & $13 / 16$ & $768 / 919$ & FMTC & '?' \\
\hline $14 / 15$ & \multicolumn{2}{|c|}{ V804M/S904C } & MEN 2B & $\mathrm{D}$ \\
\hline
\end{tabular}


a single adenoma to marked hyperplasia. Most individuals with HPT have no symptoms; however, hypercalciuria and renal calculi may occur. If HPT is longstanding and unrecognized, symptoms may become severe. HPT usually presents many years after the diagnosis of MTC and the average age of its onset is 38 years (Pacak et al., 2005).

Rare variants of MEN2A also exist, including MEN2A with cutaneous lichen amyloidosis (CLA); this skin lesion is located over the upper portion of the back which may appear before the onset of MTC (Donovan et al., 1989; Gagel et al., 1989; Moline and Eng, 2011). Another rare variant is MEN2A/FMTC with Hirschsprung's disease (Raue and Frank-Raue, 2012), which occurs in about 16\% of the cases (Panza et al., 2012).

The clinical course of MTC in patients with MEN2A is variable and the disease progression is associated with codon specific mutations (Eng et al., 1996; Machens et al., 2001). The majority of mutations in MEN2A kindred involve the cysteine-rich domain of the RET protein, including exons 10 and 11(Randolph and Maniar, 2000; Fishbein and Nathanson, 2012).

All individuals with an MTC-predisposing RET mutation who have not undergone prophylactic thyroidectomy demonstrate biochemical evidence of MTC by age 35 years (Cohen and Moley, 2003).

\section{Multiple Endocrine Neoplasia Type 2B}

Initial descriptions of MEN2B were reported by Wagenmann in 1922 (A, 1922 ), Froboese in 1923 (C, 1923), and then in 1966. The constellation of findings associated with MEN2B including thick lips, tongue lesions, MTC and PHEO was described in a patient and his family members by Williams and Pollock (Williams and Pollock, 1966; Williams ED, 1966 ).

MEN2B accounts for about 5-10\% of all cases affected with MEN2 syndrome (Moline and Eng, 2011). MEN2B is characterized by the early development of an aggressive form of MTC in all affected individuals (typically during the first year of life), PHEO (about 50\% of individuals), the absence of hyperparathyroidism, and visible physical stigmata such as raised bumps on the lips and tongue (caused by cutaneous neuromas), ganglioneuromas of the intestine, and asthenic marfanoid body habitus with skeletal deformations often with kyphoscoliosis or lordosis, joint laxity, decreased subcutaneous fat, and proximal muscle wasting and weakness can also be seen (Raue and Frank-Raue, 2012). The lips become prominent (or"blubbery") over time, and submucosal nodules may be present on the vermilion border of the lips (Moline and Eng, 2011). The mucosal neuromas on the tongue and lips (bumpy lips) resulting in a distinctive facial appearance, together with a marfanoid body habitus (65\%-75\%), allows for diagnosis at a first glance (Moline and Eng, 2011). Interestingly, individuals with MEN2B may be identified in infancy or early childhood by the presence of mucosal neuromas on the anterior dorsal surface of the tongue, palate, or pharynx and a distinctive facial appearance. However, early diagnosis by clinical means is difficult because of the gradual development of the typical clinical appearance during childhood (Wray et al., 2008).

About $40 \%$ of affected individuals have diffuse ganglioneuromatosis of the gastrointestinal which is responsible for the megacolon, constipation, and diarrhea that often present. Because of their similar clinical presentations, the clinician should carefully differentiate the diagnosis of Hirschsprung disease as a result of aganglioneuromatosis from MEN2B (Raue and Frank-Raue, 2012). Neuromas of the eyelids may cause thickening and eversion of the upper eyelid margins. Prominent thickened corneal nerves may be seen by slit lamp examination (Moline and Eng, 2011).

Brauckhoff et al. reported that an inability to cry tears is also one of the symptoms of MEN2B. It is the rarest form of MEN2 and accounts for 5-10\% of such cases (Brauckhoff et al., 2008).

Individuals with MEN2B who do not undergo prophylactic thyroidectomy at an early age (1 year), are likely to develop metastatic MTC at an early age. Before intervention with early prophylactic thyroidectomy, the average age of death in individuals with MEN2B was 21 years (Moline and Eng, 2011).

Patients with MEN2B often do not have a family history of the disease; in more than $50 \%$ of cases the syndrome is due to a de novo germline RET mutation, especially in exons 16 and 15 (Majidi et al., 2011; Raue and Frank-Raue, 2012)

\section{Familial Medullary Thyroid Carcinoma}

FMTC is characterized by a strong predisposition to MTC in families with a very low incidence of other endocrinopathies related to MEN2 (Raue and FrankRaue, 2012). It is also considered as a "clinical variant of MEN2A in which MTC is the only manifestation"(Moline and Eng, 2011). Another characteristic feature of FMTC is the presence of amyloid deposits between tumor cells (Moley et al., 1998; Raue and Frank-Raue, 2009). Actually, FMTC is the mildest variant in which patients have familial, often more benign MTC and by definition no incidence of other endocrine neoplasms (Öberg, 2013).

FMTC is frequently bilateral and multifocal, and is generally the least aggressive phenotype, not appearing until the second or third decade of life (Lin, 2011). FMTC has been diagnosed more frequently in recent years and is reported to account for $35-60 \%$ of all MTC cases (Raue and Frank-Raue, 2012). Regarding MTC, in FMTC, penetrance is lower and the clinical course is more benign than in MEN2A and MEN2B, with a late onset or no clinically manifesting disease, and the prognosis is relatively good. Therefore, a family history is often inadequate for establishing familial disease (Raue and Frank-Raue, 2012).

The diagnosis of FMTC can only be considered when four or more family members across a wide range of ages have or have had isolated MTC (Raue and Frank-Raue, 2009). Careful genetic and biochemical screening often reveals a family history of MTC in patients originally thought to have the sporadic form of the disease (Figlioli et al., 2013).

To avoid neglecting the risk of PHEO, strict criteria 
should be met before a family is classified as having FMTC. In the past, some believed that a kindred with FMTC should have more than 10 members with a RET mutation, multiple individuals with a RET mutation over the age of 50 years, and all members should have an adequate medical history demonstrating a lack of PHEO or PHPT (Machens et al., 2001; Machens and Dralle, 2006). In fact, the diagnosis of FMTC is based on the absence of PCC and PHPT in two or more generations within a family or by providing evidence of a RET mutation in a codon associated with susceptibility to only MTC, including codons 609, 611, 618, 620, 768, 790, 804, and 891 (Wohllk et al., 2010). In families with single affected generation or smaller families, the FMTC classification should be done cautiously, as there is the possibility of failure to PHEO and MEN2A diagnosis (Kloos et al., 2009).

\section{RET Proto Oncogene}

The location of RET proto-oncogene was determined on human chromosome $10 \mathrm{q} 11.2$ in 1985 , and the gene subsequently named RET [RE-arranged during Transfection] after it was found to be rearranged during transfection in 3T3 cell lines with DNA from lymphoma cells. In fact, it was shown to be activated by a DNA rearrangement (Takahashi et al., 1985).

After two years of RET locus identification, the genes responsible for MEN2 were found to be localized in centromeric region of chromosome 10 [10q11.21] by genetic linkage analysis in 1987 (Donis-Keller et al., 1993).

RET contains 21 exons and encodes a tyrosine kinase receptor (RTK) protein (Ceccherini et al., 1993). Its GC rich promoter locates in the nucleotide sequence of exon 1 . The main RET transcript length is 5659 base pairs and is translated to 1114 amino acid-residue protein (Machens et al., 2003). The RET protein is $170 \mathrm{KDa}$, present on the cell surface, and highly phosphorylated on tyrosine residues (Asai et al., 1995).

\section{RET Protein Kinase Structure}

RET is expressed primarily in peripheral enteric, sympathetic and sensory neurons, central motor, dopamine and noradrenaline neurons. It is also expressed in branching ureteric bud during embryogenesis and in differentiating spermatogenia (Pachnis et al., 1993; Meng et al., 2000).

$R E T$ has three different transcripts, encoding RET isoforms. RET exon 19 is present in all transcripts, however, differential splicing at the $3^{\prime}$ end of exon 19 results in transcripts where exon 19 is unspliced, spliced to exon 20, or spliced to exon 21 (Ivanchuk et al., 1998). These transcripts encode RET isoforms with distinct c-terminal ends of 9 (RET9), 51 (RET51), or 43 (RET43) amino acids. RET9 and RET51, consisting of 1072 and 1114 amino acids respectively, are the main isoforms in vivo. These two isoforms are co-expressed in most tissues but have distinct developmental roles and different gene expression profiles, suggesting possible differences in downstream regulation of cell-cell interaction pathways (Takahashi et al., 1993; Myers et al., 1995; Hickey et al., 2009). The final common amino acid for all three isoforms is a tyrosine (Y1062) which is phosphorylated during RET activation. Thus, alternative splicing places Y1062 in different amino acids contexts in the three RET isoforms, conferring different binding potentials (Arighi et al., 1997; Lorenzo et al., 1997).

RET has three domains, including an N-terminal extracellular segment which is included a ligand-binding domain, a cadherin (Ca2+-dependent cell adhesion)like domain, and a cysteine-rich domain (near the cell membrane). This domain is a ligand for an activator protein called glial cell derived neurotropic factor (GDNF) (Arighi et al., 2005).

The two other domains are a hydrophobic transmembrane domain, and an intracellular TK domain (Arighi et al., 2005). The TK domain contains multiple tyrosine residues (16 in RET9 and 18 in RET51), two of which, at positions 1019 and 1051, are only present in RET51 (Asai et al., 1995). The transmembrane domain ensures the close proximity of the RET monomers through noncovalent receptor-receptor interactions. The intracellular portion contains two TK subdomains, which are phosphorylated during receptor activation and are involved in the activation of the intracellular signaling pathways (de Groot et al., 2006; Colombo-Benkmann et al., 2008).

\section{RET Protein Kinase Function}

The ligands of the RET receptor TK are growth factors belonging to the GDNF family or GDNF family ligands (GFLs), including GDNF, neurturin (NRTN), artemin (ARTN), and persephin (PSPN). Without the ligand, RET is monomeric, unphosphorylated, and inactive. Binding of the ligand due to GFR $\alpha$ co-receptors to the extracellular domain of RET induces receptor dimerization and autophosphorylation, creating intracellular binding sites for signaling proteins with the subsequent activation of multiple signaling pathways (Phay and Shah, 2010). In other words, once GFL binds to RET receptor, an intracytoplasmic domain within upstream portion of RET is autophosphorylated, which stabilizes the protein, and is necessary for further downstream activity of $R E T$ autophosphorylation cascade. In fact, phosphorylation of Tyr981, as well as of Tyr1015, Tyr1062 and Tyr1096, is important for initiating intracellular signal transduction processes (Airaksinen and Saarma, 2002). RET signaling is thought to provide growth and survival signaling via the RAF-MEK-ERK and PI3K-AKT-mTOR pathways (Takahashi, 2001).

\section{RET Proto Oncogene Mutations}

$R E T$ was one of the first RTKs found to play a role in neoplasia (Figlioli et al., 2013). Interestingly, oncogenic activation of RET has been shown to activate both PI3K/ AKT- and RAS/RAF/MAPK-dependent cell signaling (Segouffin-Cariou and Billaud, 2000; Raue and FrankRaue, 2010). Various autosomal dominantly inherited mutations have been shown to cause a constitutive activation of RET (Figlioli et al., 2013). Both gain- and loss-of-function of RET mutations have been identified in 
human diseases (Takahashi, 2001; Santoro et al., 2004). Gain of function mutations in RET have been implicated in the pathogenesis of several forms of thyroid cancer which leads to autophosphorylation of tyrosine sites within RET (Salehian and Samoa, 2013). Single point mutations in the extracellular domain of RET have been implicated in the malignant transformation of cells that originate from the neural crest during embryogenesis (Manie et al., 2001), such as the parafollicular cells of the thyroid. These point mutations can occur as both germline and somatic mutations (Boikos and Stratakis, 2008).

Germline missense mutations of RET are associated with MEN2A, MEN2B, and FMTC, as described previously (Takahashi et al., 1985), whereas sporadic MTC is thought to be due to a somatic mutation in the tumor cells (Romei et al., 1996). RET mutations are mostly missense and located in exons 10, 11 (extracellular domain of RET), 13, 14, 15, and 16 (in the TK domain) (Segouffin-Cariou and Billaud, 2000; Raue and FrankRaue, 2010; Hedayati et al., 2011) (Table1). Mutation of the extracellular cysteine in codon 634 in exon 11 of RET causes ligand-independent dimerization of receptor molecules, enhanced phosphorylation of intracellular substrates and cell transformation. Mutation of the intracellular TK (for example codon 918) has no effect on receptor dimerization but does cause constitutive activation of intracellular signaling pathways and also results in cellular transformation (Machens et al., 2003).

Further, rearrangements of RET (RET/PTC) are associated with papillary thyroid carcinoma (PTC) commonly seen in tumors of children and tumors associated with radiation exposure (Tallini and Asa, 2001).

RET loss-of-function mutations are associated with a genetic disorder of neural crest development known as Hirschsprung disease (Arighi et al., 2005), which is a congenital absence of the enteric nervous system in the hindgut and lack of ganglion cells in the colon (Edery et al., 1994). Interestingly, some overlap has been reported between MEN2 and Hirshprung's phenotypes [especially MEN2A/Hirshprung] (Oberg, 2013).

The various RET mutations relate not only to the disease phenotype but also the clinical aggressiveness of MTC (Eng et al., 1996).

Analysis of RET in families with MEN2A and FMTC revealed that nearly all these families have germline mutations, and that only those family members with the germline missense mutations have the disease (FrankRaue et al., 2007). Actually, germline RET mutations are observed in $98 \%$ of MEN2A, $95 \%$ of MEN 2B, and $88 \%$ of FMTC kindreds (Figlioli et al., 2013). Significantly,

Table 2.American Thyroid Association Risk Level and Prophylactic Thyroidectomy Testing and Therapy (Kloos et al., 2009)

\begin{tabular}{|c|c|c|c|c|}
\hline ATA risk level & Age of RET testing & Age of required first US & Age of required first serum $\mathrm{Ct}$ & Age of prophylactic surgery \\
\hline $\mathrm{D}$ & $\begin{array}{l}\text { ASAP and within } \\
\text { the } 1^{\text {st }} \text { year of life }\end{array}$ & $\begin{array}{l}\text { ASAP and within the } \\
1^{\text {st }} \text { year of life }\end{array}$ & $\begin{array}{l}6 \text { months, if surgery } \\
\text { not already done }\end{array}$ & $\begin{array}{l}\text { ASAP and within the } \\
1^{\text {st }} \text { year of life }\end{array}$ \\
\hline $\mathrm{C}$ & $<3-5$ years & $>3-5$ years & $>3-5$ years & Before age 5 years \\
\hline B & $<3-5$ years & $>3-5$ years & $>3-5$ years & $\begin{array}{l}\text { Consider surgery before age } 5 \text {. } \\
\text { May delay surgery beyond age } 5 \\
\text { years if stringent criteria are met. }\end{array}$ \\
\hline A & $<3-5$ years & $>3-5$ years & $>3-5$ years & $\begin{array}{l}\text { May delay surgery beyond age } 5 \\
\text { years if stringent criteria are met. }\end{array}$ \\
\hline
\end{tabular}

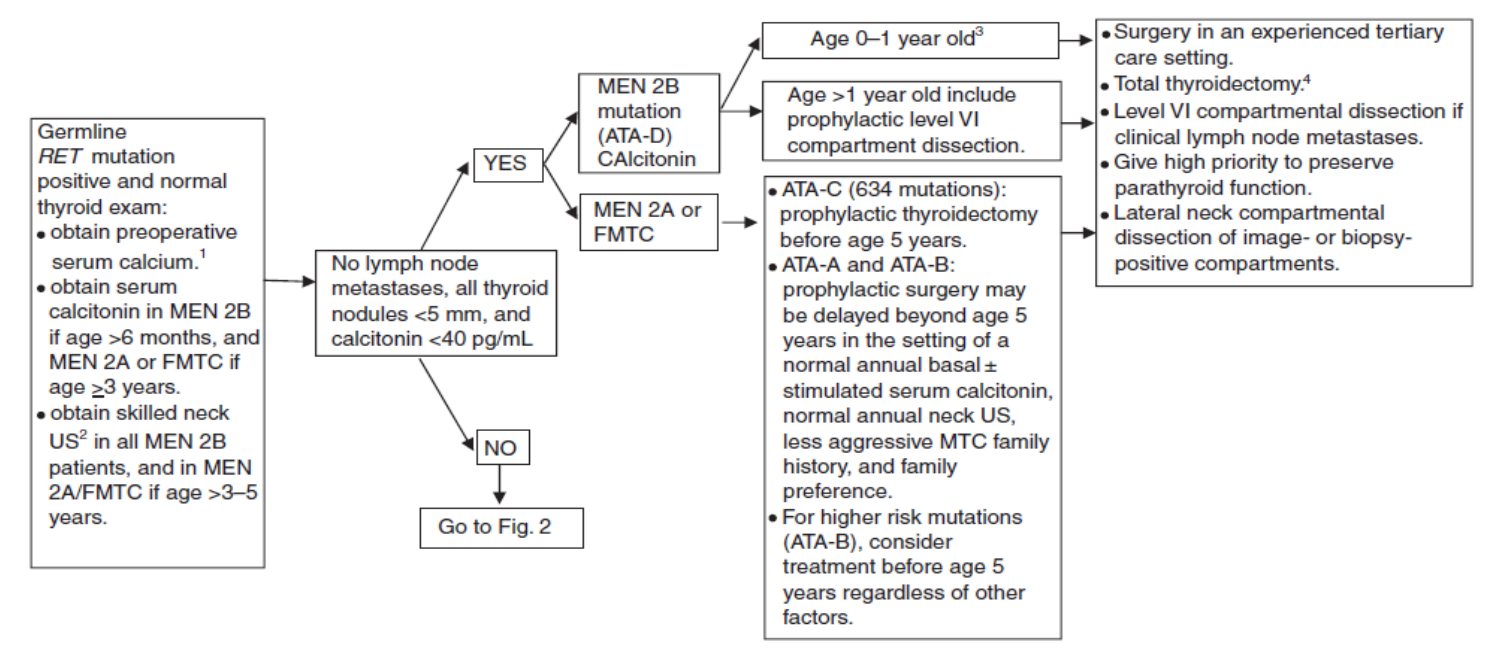

${ }^{1}$ Treat hyperparathyroidism with 4 gland resection and autograft to heterotopic site, or subtotal parathyroidectomy. Consider cryopreservation. PHEO preoperative screening should begin by age 8 years for MEN 2B and mutated RET codons 634 and 630 ; otherwise by age 20 years for other RET mutations.

${ }^{2} \mathrm{Neck}$ US to include the superior mediastinum and central and lateral neck compartments.

${ }^{3}$ Insufficient data to recommend routine prophylactic level $\mathrm{VI}$ compartment dissection.

${ }^{4}$ Parathyroid glands resected or devascularized should be autografted in the neck in RET-negative, MEN 2B, and FMTC patients, while MEN 2A glands should be auto graphed to a heterotopic site. 
$30 \%-50 \%$ of sMTC tumors also bear somatic RET mutations, the majority resembling those seen in the most aggressive hereditary form, MEN2B (Elisei et al., 2008; Agrawal et al., 2013). Most of these are the M918T mutation. RET mutations in sMTC cases were associated with increased risk of nodal and distant metastases, as well as a significantly inferior survival rate (Strosberg, 2013).

Activating mutations of RET involving exons 10, 11 , $13,14,15$ have been proved to cause MEN2A. The most common mutations involve exons 10 and 11 encoding the highly conserved cysteine-rich domain (Marx and Stratakis, 2005). The mutations for MEN2A are mostly located in exon 10, including codons $609,611,618$, and $620(10-15 \%)$, and exon 11, including codons 630 and 634 (80-85\%) (Donis-Keller et al., 1993; Mulligan et al., 1993; Eng et al., 1996). Hyperparathyroidism in MEN2A shows a strong association with the presence of a mutation in codon 634 and C634R in particular (Eng et al., 1996; Hedayati et al., 2006; Alvandi et al., 2011; Masbi et al., 2014). Other uncommon mutations in the intracellular TK domain have also been reported in MEN2A kindred (Marx and Stratakis, 2005; Hoff and Hoff, 2007).

Pheochromocytoma is associated with exon 634 and 918 mutations in approximately $50 \%$ of patients, with exon 10 mutations (codons 609, 611,618 and 620) in up to $17 \%$ of patients (Frank-Raue et al., 2011), and rarely with mutations in exons 13-15 (codons 791 and 804) (Machens et al., 2005; Quayle et al., 2007) and exon 8 (codon 533) (Donis-Keller et al., 1993; Mulligan et al., 1993; Eng et al., 1996).

There is a significant age-related progression from $\mathrm{CCH}$ to MTC that correlates with the transformative capacity for the particular RET mutation. C-cells are more susceptible to oncogenic RET activation than adrenal medullary or parathyroid cells (Machens et al., 2003).

The mutations characteristic of FMTC also occur in exons 10 and 11 . However, non-cysteine point mutations also have been found in exon 8 (codons 532 and 533), exon 13 (codons 768,790, and 791), exon 14 (codons 804 and 844), exon 15 (codon 891), and exon 16 (codon 912) (Mulligan et al., 1994; Eng et al., 1996; Kouvaraki et al., 2005). A recently meta-analysis has shown that since 1993, a total of 39 different RET germline mutations were identified in FMTC patients from different families. Except for a 9-bp duplication (after codon 531, exon8), all mutations were missense type and were scattered among the exons $5,8,10,11,13,14,15$, and 16. In FMTC, specific germline RET mutations were widely correlated with age-specific penetrance of cancer development and nodal metastases (Figlioli et al., 2013). Altogether, FMTC has been most commonly associated with mutations in codons $609,611,618$, and 620 in exon 10; codon 768 in exon 13; and codon 804 in exon 14. When FMTC is associated with mutations in codon 634 in exon 11, it is almost never C634R and is most commonly C634Y (Eng et al., 1996).

About $95 \%$ of MEN2B patients carry a M918T mutation within exon 16 and $5 \%$ have an $\mathrm{A} 883 \mathrm{~F}$ mutation in exon15 (Iwashita et al., 1996; Miyauchi et al., 1999). Mutation in codon 918 gives a more aggressive phenotype. Rare MEN2B patients compound heterozygotes for RET mutations (V804M/Y806C) were also observed (Gimm et al., 1997; Miyauchi et al., 1999).

\section{RET Genetic Screening:}

Genetic testing for RET germline mutation (Figures 1-5) has shown $100 \%$ sensitivity and specificity to



\footnotetext{
${ }^{1}$ Treat hyperparathyroidism with 4 gland resection and autograft to heterotopic site, or subtotal parathyroidectomy. Consider cryopreservation. ${ }^{2}$ Ideally performed with genetics counseling and completed preoperatively.

${ }^{3} \mathrm{PHEO}$ preoperative screening should begin by age 8 years for MEN 2B and mutated RET codons 634 and 630 ; and by age 20 years for other RET mutations.

${ }^{4}$ Parathyroid glands resected or devascularized should be autografted in the neck in RET-negative, MEN 2B, and FMTC patients, while MEN 2A glands should be autografted to a heterotopic site.

${ }^{5}$ Consider external beam radiation of TNM stage T4 disease to prevent recurrent local disease.

FNA, fine-needle aspiration biopsy.
}

Figure 2. Initial Diagnosis and Therapy of Clinically Apparent Disease (after Kloos et al., 2009) 




'Parathyroid glands resected or devascularized should be autografted in the neck in RET-negative, MEN 2B, and FMTC patients, while MEN 2A glands should be autografted to a heterotopic site.

${ }^{2}$ Consider external beam radiation of $\mathrm{T}_{4}$ disease to prevent recurrent local disease.

${ }^{3}$ Observation of nonthreatening locoregional disease $<1 \mathrm{~cm}$ may be considered.

Figure 3. Initial Evaluation and Treatment of Postoperative Patients (after Kloos et al., 2009)

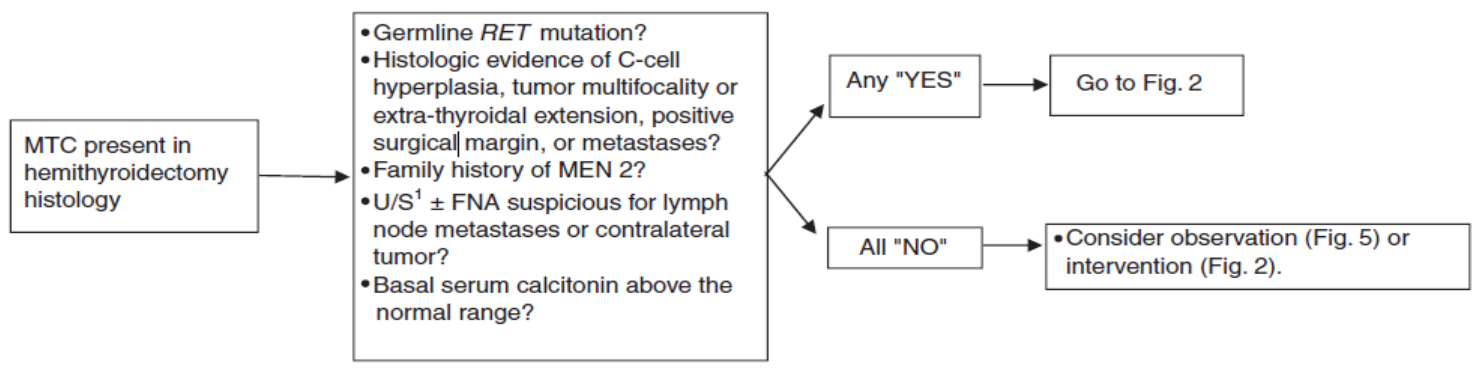

${ }^{1}$ Neck US to include the superior mediastinum and central and lateral neck compartments.

Figure 4. Management of MTC after Hemithyroidectomy (after Kloos et al., 2009)

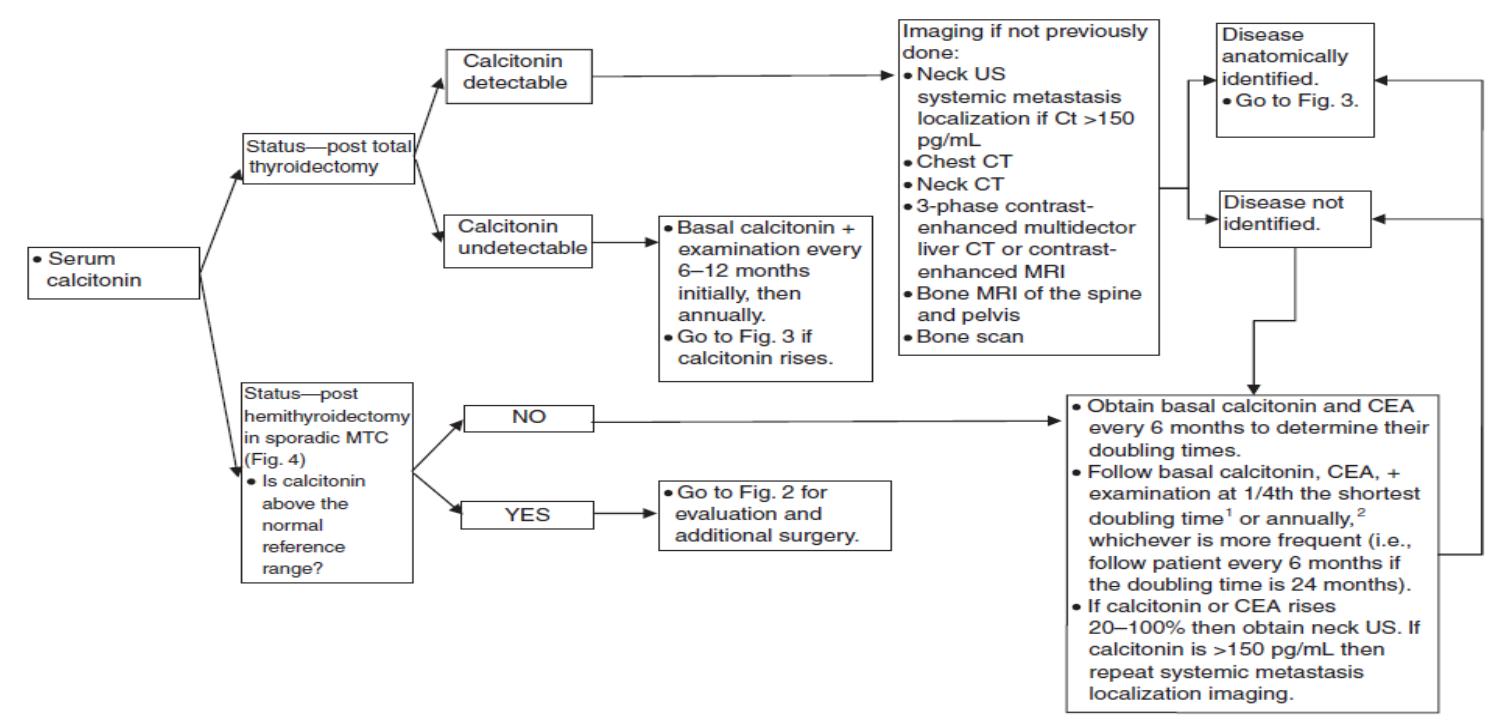

${ }^{1}$ Doubling time may be estimated or optimally calculated by fitting data to single exponentials by nonlinear least-square analysis (calculator available at www.thyroid.org).

${ }^{2}$ Patients with RET mutations associated with PHEO or primary hyperparathyroidism should be screen annually beginning at age 8 years in MEN 2B and mutated RET codons 634 and 630, and from age 20 years in carriers of other MEN 2A RET mutations, while those associated only with FMTC should be screened at least periodically.

Figure 5. Long Term Surveillance (after Kloos et al., 2009)

2114 Asian Pacific Journal of Cancer Prevention, Vol 16, 2015 
identify individuals at risk of MTC development. Use of this genetic assay allows earlier and more definitive identification and clinical management of persons with a familial risk for MTC when compared to the existing standard of annual biochemical monitoring, such as serum calcitonin. Once a person is found to be positive for a RET mutation, they must be carefully counseled. At-risk family members need to be identified and should undergo genetic testing, because even asymptomatic patients that are identified as RET mutation carriers can be offered a prophylactic thyroidectomy (Sippel et al., 2008).

Since hMTC can be prevented with prophylactic thyroidectomy, the American Thyroid Association (ATA) recommends that all patients with MTC be offered germline RET testing (Strosberg, 2013). Recommendations for the timing of prophylactic thyroidectomy and the extent of surgical resection is based on a model which uses the genotype-phenotype correlations to stratify mutations into risk levels (A-D). ATA level D (ATA-D) mutations carry the highest risk for MTC. These mutations include codons 883 (exon 15) and 918 (exon 16) that are associated with the youngest age of onset and highest risk of metastases and mortality. ATA level C (ATA-C) mutations carry a lower, yet still high risk of aggressive MTC and include mutations at codon 634 (exon 11). ATA level B (ATA-B) mutations carry a lower risk for aggressive MTC mutations and include mutations at codons 609, 611, 618, 620 (exon 10), and 630 (exon 11). ATA level A (ATA-A) mutations carry the "least high" risk. Compared to ATA-B mutation carriers of the same age, these patients have lower serum calcitonin levels, lower tumor stage, and a higher rate of biochemical cure when they undergo prophylactic thyroidectomy at age $\geq 4$ years (Frank-Raue et al., 2006). ATA-A mutations include RET mutations at codons 768 , 790, 791 (exon 13), 804 (exon 14), and 891 (exon 15). (Table2) (Kloos et al., 2009).

ATA chose to create specific MTC Clinical Guidelines that would bring together and update the diverse MTC literature and combine it with evidence-based medicine and input from a panel of expert clinicians (Figure 1-5) (Kloos et al., 2009).

\section{References}

A W (1922 ). Multiple neurome des Auges und der Zunge. Ber Dtsch Ophthal, 43, 282-5.

Agrawal N, Jiao Y, Sausen M, et al (2013). Exomic sequencing of medullary thyroid cancer reveals dominant and mutually exclusive oncogenic mutations in RET and RAS. $J$ Clin Endocrinol Metab, 98, 364-9.

Airaksinen MS, Saarma M (2002). The GDNF family: signalling, biological functions and therapeutic value. Nat Rev Neurosci, 3, 383-94.

AJ J (1906). Ein fall von metastasierenden amyloidtumoren (lymphosarcoma). Virchows Arch, 185, 251-67.

Alvandi E, Akrami SM, Chiani M, et al (2011). Molecular analysis of the $R E T$ proto-oncogene key exons in patients with medullary thyroid carcinoma: a comprehensive study of the Iranian population. Thyroid, 21, 373-82.

Arighi E, Alberti L, Torriti F, et al (1997). Identification of Shc docking site on Ret tyrosine kinase. Oncogene, 14, 773-82.

Arighi E, Borrello MG, Sariola H (2005). RET tyrosine kinase signaling in development and cancer. Cytokine Growth Factor Reviews, 16, 441-67.

Asai N, Iwashita T, Matsuyama M, et al (1995). Mechanism of activation of the ret proto-oncogene by multiple endocrine neoplasia 2A mutations. Mol Cell Biol, 15, 1613-9.

Boikos SA, Stratakis CA (2008). Molecular mechanisms of medullary thyroid carcinoma: current approaches in diagnosis and treatment. Histol Histopathol, 23, 109-16.

Brandi ML, Gagel RF, Angeli A, et al (2001). Guidelines for diagnosis and therapy of MEN type 1 and type 2. J Clin Endocrinol Metab, 86, 5658-71.

Brauckhoff M, Machens A, Hess S, et al (2008). Premonitory symptoms preceding metastatic medullary thyroid cancer in MEN 2B: An exploratory analysis. Surg, 144, 1044-51.

C F (1923). Das aus markhaltigen nervenfascern bestehende gangliezellenlose echte neurom in rankenformzugleich ein beitrag zu den nervosen Geschwulsten der zunge und des augenlides. Virchows Arch Pathol Anat, 240, 312-27.

Campbell MJ, Seib CD, Gosnell J (2013). Vandetanib and the management of advanced medullary thyroid cancer. Curr Opin Oncol, 25, 39-43.

Ceccherini I, Bocciardi R, Luo Y, et al (1993). Exon structure and flanking intronic sequences of the human RET protooncogene. Biochem Biophys Res Commun, 196, 1288-95.

Cohen MS, Moley JF (2003). Surgical treatment of medullary thyroid carcinoma. J Intern Med, 253, 616-26.

Colombo-Benkmann M, Li Z, Riemann B, et al (2008). Characterization of the RET protooncogene transmembrane domain mutation S649L associated with nonaggressive medullary thyroid carcinoma. Eur J Endocrinol, 158, 811-6.

Costante G, Meringolo D, Durante C, et al (2007). Predictive value of serum calcitonin levels for preoperative diagnosis of medullary thyroid carcinoma in a cohort of 5817 consecutive patients with thyroid nodules. J Clin Endocrinol Metab, 92, 450-5.

Cushma Jr P (1962). Familial endocrine tumors: Report of two unrelated kindred affected with pheochromocytomas, one also with multiple thyroid carcinomas. Am J Med, 32, 352-60.

de Groot JW, Links TP, Plukker JT, et al (2006). RET as a diagnostic and therapeutic target in sporadic and hereditary endocrine tumors. Endocr Rev, 27, 535-60.

Donis-Keller H, Dou S, Chi D, et al (1993). Mutations in the RET proto-oncogene are associated with MEN 2A and FMTC. Hum Mol Genet, 2, 851-6.

Donovan DT, Levy ML, Furst EJ, et al (1989). Familial cutaneous lichen amyloidosis in association with multiple endocrine neoplasia type 2A: a new variant. Henry Ford Hosp Med J, 37, 147-50.

Edery P, Lyonnet S, Mulligan LM, et al (1994). Mutations of the RET proto-oncogene in Hirschsprung's disease. Nature, 367, 378-80.

Elisei R, Cosci B, Romei C, et al (2008). Prognostic significance of somatic RET oncogene mutations in sporadic medullary thyroid cancer: a 10-year follow-up study. J Clin Endocrinol Metab, 93, 682-7.

Eng C, Clayton D, Schuffenecker I, et al (1996). The relationship between specific $R E T$ proto-oncogene mutations and disease phenotype in multiple endocrine neoplasia type 2 . International RET mutation consortium analysis. JAMA, 276, 1575-9.

Figlioli G, Landi S, Romei C, et al (2013). Medullary thyroid carcinoma (MTC) and RET proto-oncogene: Mutation spectrum in the familial cases and a meta-analysis of studies on the sporadic form. Mutat Res Rev Mutat Res, 752, 36-44.

Fishbein L, Nathanson KL (2012). Pheochromocytoma and paraganglioma: understanding the complexities of the 
genetic background. Cancer Genetics, 205, 1-11.

Frank-Raue K, Buhr H, Dralle H, et al (2006). Long-term outcome in 46 gene carriers of hereditary medullary thyroid carcinoma after prophylactic thyroidectomy: impact of individual RET genotype. Eur J Endocrinol, 155, 229-36.

Frank-Raue K, Rondot S, Schulze E, et al (2007). Change in the spectrum of RET mutations diagnosed between 1994 and 2006. Clin Lab, 53, 273-82.

Frank-Raue K, Rybicki LA, Erlic Z, et al (2011). Risk profiles and penetrance estimations in multiple endocrine neoplasia type $2 \mathrm{~A}$ caused by germline $R E T$ mutations located in exon 10. Hum Mutat, 32, 51-8.

Gagel RF, Levy ML, Donovan DT, et al (1989). Multiple endocrine neoplasia type 2a associated with cutaneous lichen amyloidosis. Ann Intern Med, 111, 802-6.

Gimm O, Marsh DJ, Andrew SD, et al (1997). Germline dinucleotide mutation in codon 883 of the RET protooncogene in multiple endocrine neoplasia type $2 \mathrm{~B}$ without codon 918 mutation. J Clin Endocrinol Metab, 82, 3902-4.

Girelli ME, Nacamulli D, Pelizzo MR, et al (1998). Medullary thyroid carcinoma: clinical features and long-term follow-up of seventy-eight patients treated between 1969 and 1986. Thyroid, 8, 517-23.

Hazard JB, Hawk WA, Crile G, (1959). Medullary (solid) carcinoma of the thyroid; a clinicopathologic entity. J Clin Endocrinol Metab, 19, 152-61.

Hedayati M, Nabipour I, Rezaei-Ghaleh N, et al (2006). Germline RET mutations in exons 10 and 11: an Iranian survey of 57 medullary thyroid carcinoma cases. Med $J$ Malaysia, 61, 564-9.

Hedayati M, Zarif Yeganeh M, Sheikhol Eslami S, et al (2011). Predominant RET germline mutations in exons 10, 11, and 16 in Iranian patients with hereditary medullary thyroid carcinoma. J Thyroid Res, 2011, 264248.

Hickey JG, Myers SM, Tian X, et al (2009). RET-mediated gene expression pattern is affected by isoform but not oncogenic mutation. Genes Chromosomes Cancer, 48, 429-40.

Hoff AO, Hoff PM (2007). Medullary Thyroid Carcinoma. Hematology Oncol Clin North Am, 21, 475-88.

Ivanchuk SM, Myers SM, Mulligan LM (1998). Expression of RET3' splicing variants during human kidney development. Oncogene, 16, 991-6.

Iwashita T, Asai N, Murakami H, et al (1996). Identification of tyrosine residues that are essential for transforming activity of the ret proto-oncogene with MEN2A or MEN2B mutation. Oncogene, 12, 481-7.

Kebebew E, Ituarte PH, Siperstein AE, et al (2000). Medullary thyroid carcinoma: clinical characteristics, treatment, prognostic factors, and a comparison of staging systems. Cancer, 88, 1139-48.

Kloos RT, Eng C, Evans DB, et al (2009). Medullary thyroid cancer: management guidelines of the American thyroid association. Thyroid, 19, 565-612.

Kouvaraki MA, Shapiro SE, Perrier ND, et al (2005). RET proto-oncogene: a review and update of genotype-phenotype correlations in hereditary medullary thyroid cancer and associated endocrine tumors. Thyroid, 15, 531-44.

Leboulleux S, Baudin E, Travagli JP, et al (2004). Medullary thyroid carcinoma. Clin Endocrinol (Oxf), 61, 299-310.

Lin CC (2011). RET mutations and medullary thyroid cancer. $J$ Formos Med Assoc, 110, 731; author reply 2.

LiVolsi VA (1997). C cell hyperplasia/neoplasia. J Clin Endocrinol Metab, 82, 39-41.

Lorenzo MJ, Gish GD, Houghton C, et al (1997). RET alternate splicing influences the interaction of activated RET with the SH2 and PTB domains of Shc, and the SH2 domain of Grb2. Oncogene, 14, 763-71.
Machens A, Brauckhoff M, Holzhausen HJ, et al (2005). Codonspecific development of pheochromocytoma in multiple endocrine neoplasia type 2. J Clin Endocrinol Metab, 90, 3999-4003.

Machens A, Dralle H (2006). Multiple endocrine neoplasia type 2 and the RET protooncogene: from bedside to bench to bedside. Molec Cell Endocrinol, 247, 34-40.

Machens A, Gimm O, Hinze R, et al (2001). Genotype-phenotype correlations in hereditary medullary thyroid carcinoma: oncological features and biochemical properties. J Clin Endocrinol Metab, 86, 1104-9.

Machens A, Hauptmann S, Dralle H (2007). Increased risk of lymph node metastasis in multifocal hereditary and sporadic medullary thyroid cancer. World J Surg, 31, 1960-5.

Machens A, Niccoli-Sire P, Hoegel J, et al (2003). Early malignant progression of hereditary medullary thyroid cancer. $N$ Engl J Med, 349, 1517-25.

Majidi M, Haghpanah V, Hedayati M, et al (2011). A family presenting with multiple endocrine neoplasia type $2 \mathrm{~B}$ : A case report. J Med Case Rep, 5, 587.

Manie S, Santoro M, Fusco A, et al (2001). The RET receptor: function in development and dysfunction in congenital malformation. Trends Genet, 17, 580-9.

Marx SJ, Stratakis CA (2005). Multiple endocrine neoplasia-introduction. J Intern Med, 257, 2-5.

Masbi MH, Mohammadiasl J, Galehdari H, et al (2014). Characterization of wild-type and mutated RET protooncogene associated with familial medullary thyroid cancer. Asian Pac J Cancer Prev, 15, 2027-33.

Meng X, Lindahl M, Hyvonen ME, et al (2000). Regulation of cell fate decision of undifferentiated spermatogonia by GDNF. Science, 287, 1489-93.

Miyauchi A, Futami H, Hai N, et al (1999). Two germline missense mutations at codons 804 and 806 of the RET proto-oncogene in the same allele in a patient with multiple endocrine neoplasia type 2B without codon 918 mutation. Jpn J Cancer Res, 90, 1-5.

Modigliani E, Cohen R, Campos JM, et al (1998). Prognostic factors for survival and for biochemical cure in medullary thyroid carcinoma: results in 899 patients. The GETC Study Group. Groupe d'etude des tumeurs a calcitonine. Clin Endocrinol (Oxf), 48, 265-73.

Moley JF, DeBenedetti MK (1999). Patterns of nodal metastases in palpable medullary thyroid carcinoma: recommendations for extent of node dissection. Ann Surg, 229, 880-7.

Moley JF, Debenedetti MK, Dilley WG, et al (1998). Surgical management of patients with persistent or recurrent medullary thyroid cancer. J Intern Med, 243, 521-6.

Moline J, Eng C (2011). Multiple endocrine neoplasia type 2: an overview. Genet Med, 13, 755-64.

Mulligan LM, Eng C, Healey CS, et al (1994). Specific mutations of the RET proto-oncogene are related to disease phenotype in MEN 2A and FMTC. Nat Genet, 6, 70-4.

Mulligan LM, Kwok JB, Healey CS, et al (1993). Germ-line mutations of the RET proto-oncogene in multiple endocrine neoplasia type 2A. Nature, 363, 458-60.

Myers SM, Eng C, Ponder BA, et al (1995). Characterization of RET proto-oncogene 3' splicing variants and polyadenylation sites: a novel C-terminus for RET. Oncogene, 11, 2039-45.

Oberg K (2013). The genetics of neuroendocrine tumors. Sem Oncol, 40, 37-44.

Pacak K, Ilias I, Adams KT, et al (2005). Biochemical diagnosis, localization and management of pheochromocytoma: focus on multiple endocrine neoplasia type 2 in relation to other hereditary syndromes and sporadic forms of the tumour. $J$ Intern Med, 257, 60-8.

Pachnis V, Mankoo B, Costantini F (1993). Expression of 
the c-ret proto-oncogene during mouse embryogenesis. Development, 119, 1005-17.

Panza E, Knowles CH, Graziano C, et al (2012). Genetics of human enteric neuropathies. Progress Neurobiology, 96, 176-89.

Phay JE, Shah MH (2010). Targeting RET receptor tyrosine kinase activation in cancer. Clin Cancer Res, 16, 5936-41.

Quayle FJ, Fialkowski EA, Benveniste R, et al (2007). Pheochromocytoma penetrance varies by RET mutation in MEN 2A. Surgery, 142, 800-5.

Quayle FJ, Moley JF (2005). Medullary thyroid carcinoma: management of lymph node metastases. Curr Treat Options Oncol, 6, 347-54.

Randolph GW, Maniar D (2000). Medullary carcinoma of the thyroid. Cancer Control, 7, 253-61.

Raue F, Frank-Raue K (2009). Genotype-phenotype relationship in multiple endocrine neoplasia type 2. Implications for clinical management. Hormones (Athens), 8, 23-8.

Raue F, Frank-Raue K (2010). Update multiple endocrine neoplasia type 2. Fam Cancer, 9, 449-57.

Raue F, Frank-Raue K (2012). Genotype-phenotype correlation in multiple endocrine neoplasia type 2. Clinics, 67, 69-75.

Roman S, Lin R, Sosa JA (2006). Prognosis of medullary thyroid carcinoma: demographic, clinical, and pathologic predictors of survival in 1252 cases. Cancer, 107, 2134-42.

Romei C, Cosci B, Renzini G, et al (2011). RET genetic screening of sporadic medullary thyroid cancer (MTC) allows the preclinical diagnosis of unsuspected gene carriers and the identification of a relevant percentage of hidden familial MTC (FMTC). Clin Endocrinol, 74, 241-7.

Romei C, Elisei R, Pinchera A, et al (1996). Somatic mutations of the ret protooncogene in sporadic medullary thyroid carcinoma are not restricted to exon 16 and are associated with tumor recurrence. J Clin Endocrinol Metab, 81, 161922.

Saad MF, Ordonez NG, Rashid RK, et al (1984). Medullary carcinoma of the thyroid. A study of the clinical features and prognostic factors in 161 patients. Medicine, 63, 319-42.

Salehian B, Samoa R (2013). RET Gene abnormalities and thyroid disease: who should be screened and when. J Clin Res Pediatr Endocrinol, 5, 70-8.

Santoro M, Melillo RM, Carlomagno F, et al (2004). Minireview: RET: normal and abnormal functions. Endocrinology, 145, 5448-51.

Scollo C, Baudin E, Travagli JP, et al (2003). Rationale for central and bilateral lymph node dissection in sporadic and hereditary medullary thyroid cancer. J Clin Endocrinol Metab, 88, 2070-5.

Segouffin-Cariou C, Billaud M (2000). Transforming ability of MEN2A-RET requires activation of the phosphatidylinositol 3-kinase/AKT signaling pathway. J Biol Chem, 275, 356876.

Siegel R, Naishadham D, Jemal A (2012). Cancer statistics, 2012. CA Cancer J Clin, 62, 10-29.

Sippel RS, Kunnimalaiyaan M, Chen H (2008). Current management of medullary thyroid cancer. Oncologist, 13, 539-47.

Sipple JH (1961). The association of pheochromocytoma with carcinoma of the thyroid gland. Am J Med, 31, 163-6.

Steiner AL, Goodman AD, Powers SR (1968). Study of a kindred with pheochromocytoma, medullary thyroid carcinoma, hyperparathyroidism and Cushing's disease: multiple endocrine neoplasia, type 2. Medicine, 47, 371-409.

Strosberg JR (2013). Update on the management of unusual neuroendocrine tumors: pheochromocytoma and paraganglioma, medullary thyroid cancer and adrenocortical carcinoma. Semi Oncol, 40, 120-33.
Takahashi M (2001). The GDNF/RET signaling pathway and human diseases. Cytokine Growth Factor Rev, 12, 361-73.

Takahashi M, Asai N, Iwashita T, et al (1993). Characterization of the ret proto-oncogene products expressed in mouse $\mathrm{L}$ cells. Oncogene, 8, 2925-9.

Takahashi M, Ritz J, Cooper GM (1985). Activation of a novel human transforming gene, ret, by DNA rearrangement. Cell, 42, 581-8.

Tallini G, Asa SL (2001). RET oncogene activation in papillary thyroid carcinoma. Adv Anat Pathol, 8, 345-54.

Williams ED (1966). Histogenesis of medullary carcinoma of the thyroid. J Clin Pathol, 19, 114-8.

Williams ED PD (1966 ). Multiple mucosal neuromata with endocrine tumours: a syndrome allied to von Recklinghausen's disease. J Pathol Bacteriol, 91, 71-80.

Williams ED, Pollock DJ (1966). Multiple mucosal neuromata with endocrine tumours: a syndrome allied to von Recklinghausen's disease. J Pathol Bacteriol, 91, 71-80.

Wohllk N, Schweizer H, Erlic Z, et al (2010). Multiple endocrine neoplasia type 2. Best Pract Res Clin Endocrinol Metab, 24, 371-87.

Wray CJ, Rich TA, Waguespack SG, et al (2008). Failure to recognize multiple endocrine neoplasia 2B: more common than we think? Ann Surg Oncol, 15, 293-301.

Xu L, Wang WB, Zhao YP, et al (2012). Medullary thyroid carcinoma with nodular goiter carries an excellent prognosis. J Surg Oncol, 106, 169-73.

Zbuk KM, Eng C (2007). Cancer phenomics: RET and PTEN as illustrative models. Nat Rev Cancer, 7, 35-45. 